\title{
OTTO LEONHARD HEUBNER ZUM ACHTZIGSTEN GEBURTSTAG.
}

Zehn Jahre sind verflossen, seitdem Otro Leonhard HeubNe ${ }^{1}$ ), der Altmeister der deutschen Kinderheilkunde, als Ordinarius an der Universität Bèrlin das siebenzigste Jahr seines an Arbeit und Erfolgen reichen Lebens vollendete und wenig später aus freiem Entschlusse dem Amte entsagte, das er an zwanzig Jahre verwaltet hatte. Was er der Wissenschaft, was er insbesondere der Kinderheilkunde war, ist in den Annalen der Medizin verzeichnet; was er denen war, die ihm näher gestanden haben, was ex vor allem seinen Schülern war, das habe ich selbst damals dankbaren Herzens zu schildern versucht2). Heute nun ist es den deutschen Arzten noch einmal vergönnt, dem ausgezeichneten Forscher und Kliniker, dem Bahnbrecher der Pädiatrie, dem Lehrer und Freunde zum achtzigsten Geburtstage ihre ehrerbietigsten Grüße darzubringen.

Zehn Jahre sind verflossen - anders freilich, als sie sich malten in den Sinnen des Scheidenden und in den Sinnen der Bleibenden an jenem Tage, der die Verehrer, Freunde und Schüler des Mannes zur einfachen und doch so würde- und eindrucksvollen Feier der letzten Vorlesung zusammengeführt hatte. Wohl griff die Stunde wehmütig ans Herz; aber wer den da oben auf dem blumenbekränzten Katheder hörte und sah, wer ihn und sein Wesen und Wollen kannte, den tröstete die Erkenntnis: Hier geht kein Müder, Verbrauchter zur Ruhe, hier legt nạch getaner Arbeit einer die Bürde von Amt und Beruf nieder, der Kraft, Schwung und junges Fühlen genug besitzt, um nach einem Leben der Mühen und der Pflicht ein $z$ weites Leben der Freiheit und des freudigsten und edelsten Genießens zu beginnen. Der Tag der anderen sank, jetzt sollte der eigene Tag beginnen. Es winkte der Flug aus engem Kreise in ferne, bunte, seit den Jugendtagen ersehnte Länder, es winkte, von jeher mit der Seele gesucht, das Reich der Kunst, es winkte die freie, ungehemmte Wanderung durch die Weiten der Natur- und Geisteswissenschaften. Die Ernte war geborgen nun wollte der rüstige Schaffer in goldener Spätherbstsonne durch alle Welten fahren, bis die Winternacht anbrach.

Da kam der Krieg; es kam der Nachkrieg, der äußere, den man Frieden nennt, und der innere. Sonne und Hoffnung erloschen, Sturm und Unwetter fuhren einher, zerstörten die Scheunen, in denen des Lebens Ertrag gehäuft war, zerstörten den Traum vom gelobten Land, das das Auge so nahe erblickt hatte. Machtlos sah er seine Werke untergehen, er, wie die Hunderttausende der anderen, die vermeint hatten, fest stehe ihr Haus. Nicht nur seine Werke! Was HrubNer, wie jedem geistigen Menschen, das Schwerste scheint, ist nicht die Erschütterung der eigenen wirtschaftlichen Existenz, nicht der Verzicht auf Schmelz, Farbe und Kultur des eigenen Daseins, es ist der Zusammenbruch alles dessen, was ihm wie uns hoch und heilig galt, dem Leben Sinn und Zweck gab, es ist des Vaterlandes tiefer Sturz, es ist die Erhebung eines sinnlos waltenden Machtrausches zum Herrscher der Welt, der Niedergang alles Ethos, die Entwertung der Geistigkeit und Persönlichkeit und nicht zuletzt die drohende Vernichtung dessen, was zu allen Zeiten Deutschlands Zierde, Stolz und Größe war, des Forscher- und Findertums in Wissenschaft und Technik. Wer fühlte nicht trotz eigenen Leides die doppelte Tragik des glühenden Patrioten, solches im Alter erschauen zu müssen mit denselben Augen, die einstmals des Reiches Herrlichkeit vom ersten Leuchten bis zur strahlenden Vollendung erstehen sahen?

1) Geb. am 2I. Jan. 1843 .

Münch. med. Wochenschr. Igr3, Nr. I3.
Und dennoch steht auch heute noch HEUBNER ungebrochen, mögen auch der Jahre und des Kummers Bürde den Nacken ein wenig mehr gebeugt, die Falten des Antlitzes vertieft haben. 'Ihn hielt, der allein uns halten kann, der Wahlspruch: Arbeiten und nicht verzweifeln. Die Jahre des Krieges sahen ihn als beratenden Arzt eines Heimatlazarettes und als Sachverständigen in allen Fragen der Volkswohlfahrt und Volksernährung; zugleich und später bestellte er seinen Garten und suchte Trost im gründlichen Studium der seit jeher geliebten Musik. Daneben beschäftigten ihn astronomische Fragen, und die Unendlichkeit des Sternenhimmels gab ihm die Kraft, den Jammer unserer winzigen Erde im Lichte der Ewigkeit zu ertragen. Auch seiner Kinderheilkunde blieb er treu und eine Anzahl von Veröffentlichungen über aplastische Anämie, über die geistige Entwicklung des Kindes, über Neuropathie $u$. a. m. gaben Zeugnis von seinem unverminderten Interesse. Sogar der eigene.Körper wurde der Wissenschaft dienstbar gemacht. Wie einstmals der Dichter aus seinem großen Schmerze die kleinen Lieder machte, so machte HEUBNER aus seinen kleinen Schmerzen eine stattliche Studie, in der er die Lehre von der Oxyuriasis durch neue Tatsachen und durch neue Behädlungsvorschriften bereicherte, die allem Anschein nach einen wirklichen Fort$\mathrm{s}{ }^{*}$ ritt in der Bekämpfung dieser hartnäckigen und letzthin so weit verbreiteten Plage darstellen. Die Mühen der Reise nicht scheuend, war HEUBNER auch regelmäBiger Besucher der Versammlungen der deutschen Gesellschaft für Kinderheilkunde, bereit, den Jüngeren, die er so lange geführt, als unermüdlicher Hörer auf neuen Wegen zu folgen, bereit aber auch, als getreuer Eckehart die warnende Stimme zu erheben, wenn die Flut der mit neuen, exakten Methoden gewonnenen Einzeltatsachen das Fundament alles ärztlichen. Tuns und Denkens, die Klinik; allzu gefahrdrohend umbrandete. Der Klinik als Herrscherin und Führerin des wahren Arztes galt auch der Trinkspruch, den der einstige Schüler WIDERHOFERS, OPPOLZERS und WUNDTRLICHS den in Leipzig versammelten Kinderärzten im vorigen Jahre darbrachte; die schlichten und doch so tiefgründigen und tief empfundenen Worte des greisen Redners gestalteten das einfache Mahl zu einer würdigen Feier.

Von nah und fern waren vor Io Jahren Heubners Getreue herbeigeeilt, um vereint mit den Berlinern dem von der Stätte und von der Stadt seines Wirkens Scheidenden noch einmal ihre Verehrung zu beweisen. Um den Achtzigjährigen wird es einsamer sein. Der Zeiten Not zwingt zur Bescheidung. Wer ferne bleiben mu:B, den tröste das Bewußtsein, daß der Verzicht auf äußere Feier dem Manne nicht schwer fallen wird, der von sich selbst mit FonTANE gern zu sagen pflegte: „Ich bin so wenig feierlich.“ Er selbst aber möge fühlen, da $B$ alle, die ihm nähergetreten sind, die mit und unter ihm gearbeitet und seines Geistes einen Hauch gespürt haben, mit ihren guten Gedanken um ihn sind und ihm ihre wärmsten und ergebensten Grüße senden.

Auch ihre Wünsche? Was sollen wir dem wünschen, der jene Höhe der Jahre und der Weisheit erklommen hat, wo der Mensch wunschlos wird, und dem überdies das bittere Erlebnis gelehrt hat, daß das Schicksal ehern über die heißesten und inbrünstigsten Wünsche hinwegschreitet! Nicht wünschen, aber hoffen wollen wir, denn die Hoffnung hört niemals auf. Wir wollen hoffen, daß ihm vergönnt sei, noch jenen Tag zu grüßen, dessen Morgenröte mit flammenden Strahlen kündet: Deutschiond wird auferstehen, Deutschland wird leben.

Finkelstejn, Berlin. 